Article

\title{
Anxiety and Depression in Patients with Obstructive Sleep Apnoea before and after Continuous Positive Airway Pressure: The ADIPOSA Study
}

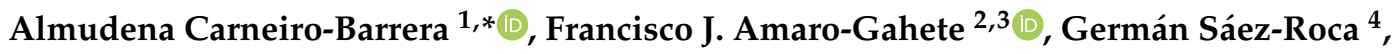 \\ Carlos Martín-Carrasco ${ }^{4}$, Jonatan R. Ruiz ${ }^{3}$ (D) and Gualberto Buela-Casal ${ }^{1}$ \\ 1 Sleep and Health Promotion Laboratory, Mind, Brain and Behaviour Research Centre (CIMCYC), \\ University of Granada, 18011 Granada, Spain; gbuela@ugr.es \\ 2 EFFECTS-262 Research group, Department of Medical Physiology, School of Medicine, University of \\ Granada, 18071 Granada, Spain; amarof@ugr.es \\ 3 PROmoting FITness and Health through physical activity research group (PROFITH), Sport and Health \\ University Research Institute (iMUDS), Department of Physical Education and Sports, Faculty of Sport \\ Sciences, University of Granada, 18071 Granada, Spain; ruizj@ugr.es \\ 4 Unidad de Trastornos Respiratorios del Sueño, Servicio de Neumología, “Virgen de las Nieves" University \\ Hospital, 18014 Granada, Spain; gsaezroca@gmail.com (G.S.-R.); cmartincarrasco@gmail.com (C.M.-C.) \\ * Correspondence: acarneiro@ugr.es
}

Received: 31 October 2019; Accepted: 27 November 2019; Published: 1 December 2019

\begin{abstract}
The prevalence and treatment response of depression and anxiety symptoms in obstructive sleep apnoea (OSA), although widely addressed in research and clinical settings, still remain unclear due to overlapping symptoms. The ADIPOSA study sought to elucidate the presence of non-overlapping symptoms of depression and anxiety in patients with moderate to severe OSA before and after continuous positive airway pressure (CPAP) treatment. Forty-eight adults aged $18-80(68.75 \%$ men) with moderate to severe OSA were enrolled in this twelve-week longitudinal single-arm trial and completed a full-night ambulatory sleep diagnostic test and an assessment of cognitive-affective depression and anxiety symptoms using the Beck-Depression Inventory-Fast Screen (BDI-FS), the State-Trait Depression Inventory (IDER) and the State-Trait Anxiety Inventory (STAI). We found no cognitive-affective depression or anxiety symptoms of clinical relevance at baseline. The amelioration of depression and anxiety symptoms after CPAP use was only statistically significant when considering anxiety-trait $(p<0.01 ; d=0.296)$ and euthymia $(p<0.05 ; d=0.402)$, the distinctive component of depression. Although dysthymia or high negative affect remained unchanged, CPAP may be effective at reducing the lack of positive affect, a well-established health-protective factor. However, not until depression and anxiety disorders related to OSA are accurately measured in clinical and research settings will it be possible to obtain robust conclusions on the occurrence and amelioration of these symptoms after treatment.
\end{abstract}

Keywords: obstructive sleep apnoea; depression; anxiety; continuous positive airway pressure; OSA; CPAP; dysthymia; euthymia; negative affect; positive affect

\section{Introduction}

Obstructive sleep apnoea (OSA) is the most common sleep-disordered breathing in the overall population, affecting up to $38 \%$ of adults, with higher prevalence in men, the elderly and in those who are overweight/obese [1]. Characterized by repeated total (apnoea) or partial (hypopnoea) upper airway collapse during sleep, OSA has globally become a major health concern due not only to its increasing prevalence-attributed to the current epidemic of obesity [2]—but also to its 
numerous and severe health-related consequences [3]. The intermittent pharyngeal obstructions during sleep lead to hypoxic and hypercapnic episodes, sleep disruption and increased/abnormal sympathetic activity [4]. These immediate consequences, in turn, may yield a vast number of physical, neurocognitive and neurobehavioral disturbances such as metabolic alterations [5,6], type II diabetes mellitus [7,8], life-threating cardiovascular diseases [9], impaired daytime functioning including memory and attention/concentration deficits [8,10], and mood and anxiety disorders [11]. Therefore, OSA is associated with higher morbidity and mortality [12], also including higher incidence of motor vehicle and workplace accidents mainly caused by excessive daytime sleepiness [13,14].

OSA is diagnosed when (1) there is a presence of five or more obstructive respiratory events per hour of sleep or per hour of recording time determined by polysomnography or out-of-centre sleep study, accompanied by one or more of the following symptoms: (a) sleepiness, fatigue, non-restorative sleep, or insomnia symptoms; (b) gasping or choking during sleep; (c) snoring and breathing interruptions reported by the bed partner; or (d) hypertension, mood disorder, cognitive dysfunction, stroke, coronary artery disease, congestive heart failure, atrial fibrillation, or type II diabetes mellitus; or (2) the polysomnography or out-of-centre sleep study shows fifteen or more obstructive respiratory events per hour of sleep or per hour of recording time, respectively, independent of the presence of other symptoms, complaints or comorbidities [15].

It has been well evidenced that depression, the most common affective disorder found in OSA [16-18], is also related to the occurrence and worsening of severe medical conditions such as metabolic and cardiovascular diseases [19], besides being a major contributing factor to non-compliance with OSA treatment [20]. According to a recent study on the prevalence of OSA in psychiatric disease [21], moderate to severe OSA can be found in $72.48 \%$ of patients with affective and psychotic disorders, so the consideration of mood disturbances should play an important role in both the evaluation and treatment of this condition. Recent epidemiological studies have also indicated that anxiety may be found in $53.9 \%$ of patients with OSA, associated with higher body mass index (BMI) and severity of OSA [11], and once again with poor compliance to OSA therapy [20].

Continuous positive airway pressure (CPAP) is the gold standard treatment for OSA [22,23], which consists of a mechanical device that prevents upper airway collapse during sleep. Numerous studies have shown that CPAP is an effective treatment in improving OSA primary outcomes such as the number of episodes of apnoea and hypopnoea per hour of sleep (i.e., apnoea-hypopnoea index, $\mathrm{AHI}$ ) and excessive daytime sleepiness, reducing therefore the majority of symptoms and consequences of this condition [24-27]. However, the effectiveness of CPAP in addressing OSA major risk factors, i.e., obesity, still remains unclear. Some studies found weight loss after a twelve-week CPAP therapy [28], while others highlighted that CPAP was not related to BMI change or induced body weight gain [29,30], although the latter may be due to increased lean mass as opposed to fat mass [31]. The latest American Academy of Sleep Medicine (AASM) guidelines therefore strongly recommend weight loss and lifestyle intervention combined with CPAP [22,32], which appears to be an effective treatment for moderate to severe OSA (i.e., AHI $\geq 15$ events/h [22]) and is the focus of current interdisciplinary clinical and medical research [3,33].

Similarly, there have been inconsistent findings regarding CPAP effects on OSA associated depression and anxiety symptoms [34]. While some clinical research found that a twelve-week CPAP use significantly reduced depression symptoms in patients with moderate to severe OSA [35-37], other studies indicated no significant changes in these psychological disturbances after CPAP treatment [38-40]. These controversial results may be explained by both (a) cofounder variables in the association between anxiety-depression and OSA, and (b) commonly used anxiety and depression scales.

OSA and depression are both independently related to obesity, increasing age, and adverse lifestyles, sharing common symptomatology such as daytime sleepiness, insomnia, fatigue and poor quality of life [34]. Consequently, improvement of OSA main outcome (i.e., AHI) after CPAP use may not necessarily result in a reduction in depressive symptoms due to potential remaining factors such as obesity and unhealthy habits [29]. In turn, anxiety and depression scales commonly used in 
order to measure baseline and posttreatment mood disturbances in patients with OSA (e.g., Hamilton Depression Rating Scale [41], Beck Depression Inventory [42], and Beck Anxiety Inventory [43]) usually include somatic symptoms found in and caused by OSA such as cardiovascular palpitations, headaches, gastrointestinal and genitourinary disturbances, loss of energy and libido, and fatigue, such that high scores of these symptoms at baseline may not necessarily signify presence of depression in patients with OSA. Therefore, further evidence including anxiety and depression measures through valid scales adjusted to medical patients-solely including non-overlapping symptoms such as cognitive-affective symptomatology - are needed not only to establish the presence of anxiety and depression disturbances in patients with OSA but also to clarify the effectiveness of CPAP therapy in reducing these specific and adverse outcomes.

The ADIPOSA study was aimed at establishing the presence of non-overlapping symptoms (i.e., cognitive-affective symptoms) of depression and anxiety in patients with moderate to severe OSA before and after a twelve-week CPAP therapy. Particularly, we hypothesised that there would be no depression nor anxiety symptomatology of clinical relevance in patients with OSA when only considering cognitive-affective symptoms. In turn, we also expected that, although a twelve-week CPAP treatment would be effective at reducing OSA primary outcome (i.e., $\mathrm{AHI}$ ), there would be no relevant changes on cognitive-affective symptoms of depression and anxiety from baseline to posttreatment.

\section{Experimental Section}

\subsection{Study Protocol and Participant's Enrolment}

The Anxiety and Depression in Patients with Obstructive Sleep Apnoea Before and After Continuous Positive Airway Pressure (ADIPOSA) study was a twelve-week longitudinal single-arm trial of CPAP treatment. The study protocol was approved by the Human Research Ethics Committees of Junta de Andalucía (0307-N-19) and registered online in a specific clinical trial database (i.e., Clinicaltrial. gov. ID: NCT03334357). The recruitment of participants was performed from April to June 2019, with patients being enrolled from the "Virgen de las Nieves" University Hospital (Granada, Spain). Eligible participants were adults aged 18-80 years, with a clinical suspicion of OSA and a BMI greater than $25 \mathrm{~kg} / \mathrm{m}^{2}$. The study exclusion criteria included current or recent CPAP treatment (i.e., during the last year) and presence of (i) other primary sleep disorders (e.g., shift work disorder, idiopathic hypersomnia and/or narcolepsy), (ii) a previously diagnosed mental disorder hindering participant's ability to perform study assessments, and/or (iii) any other severe organic diseases excluding those comorbid to OSA. Participants regularly using neuroleptic, antidepressant, sedative or hypnotic drugs, or any other medication that may cause sleep disturbances or increased daytime sleepiness were also excluded from the study.

\subsection{Procedures}

Upon meeting the inclusion criteria, informed consent signatures were obtained from potential participants with OSA willing to be enrolled. Participants were medically examined, and sociodemographic data and general health outcomes (e.g., sex, birth date, medical history, alcohol consumption and smoking history among others) were collected. Height and weight measurements were completed with an electronic scale (SECA, model 799, Electronic Column Scale, Hamburg, Germany), and were used to determine BMI by dividing weight $(\mathrm{kg})$ by the square of height $(\mathrm{m})$. An overnight sleep study and subjective measurements of daytime sleepiness, depression and anxiety symptoms were performed both at baseline and after a twelve-week CPAP treatment for all patients.

\subsubsection{Overnight Sleep Study}

A full-night ambulatory cardiorespiratory polygraphy (SOMNOScreen ${ }^{\mathrm{TM}}$ plus RM-Tele, SOMNOmedics, GmbH, Randersacker, Germany) - a widely validated and accepted OSA diagnostic tool $[22,44,45]$ - was conducted on each participant in order to determine the number of 
apnoea-hypopnoea episodes per hour of valid total recording time (i.e., AHI). Recordings were analysed by trained sleep physicians using a specific software (i.e., DOMINO v2.7, SOMNOmedics, $\mathrm{GmbH}$, Randersacker, Germany) following the AASM Manual for the Scoring of Sleep and Associated Events [46]. In accordance with the latter, AHI was defined as the number of apnoea ( $90 \%$ or greater airflow drop lasting $10 \mathrm{~s}$ or longer) and hypopnoeas (30\% or greater airflow drop lasting $10 \mathrm{~s}$ or longer and associated $\geq 3 \%$ oxygen desaturation) episodes per hour of valid total recording time [46]. Consequently, patients were diagnosed with moderate $(15$ events $/ \mathrm{h} \leq \mathrm{AHI}<30$ events/h) or severe OSA (AHI $\geq 30$ events/h).

\subsubsection{Daytime Sleepiness, Depression and Anxiety}

Subjective daytime sleepiness was assessed by the Epworth Sleepiness Scale [47,48], a widely used and reliable 8 item Likert-based scale that provides an accurate score of propensity for dozing during several daily activities from none to high (0-3). Hypersomnolence is considered when a total score greater than 10 is attained.

General and state-trait depression symptoms were assessed using the Beck-Depression Inventory-Fast Screen (BDI-FS) [49,50] and the State-Trait Depression Inventory (IDER) [51], respectively. Both instruments are reliable depression screening tools for medical patients which solely include those symptoms of depression that do not overlap with somatic disturbances caused by other physical conditions, i.e., cognitive-affective symptoms of depression. BDI-FS consists of a 7 item Likert-based scale related to sadness, pessimism, past failure, loss of pleasure, self-dislike, self-criticalness, and suicidal thoughts. Previous studies have emphasised the excellent psychometric properties and advantages of this scale for the screening of depression symptoms not only in patients with OSA [52] but also in patients with other medical conditions [53]. Similarly, IDER evaluates non-overlapping symptoms of depression but, in contrast to BDI-FS, also includes a differentiation between state and trait depression symptoms (IDER-state and IDER-trait), as well as dysthymia (high negative affect) and euthymia (lack of positive affect) components. This instrument is composed of 10 items for each subscale of state and trait depression symptoms (i.e., a total of 20 items), with answers ranging from "not at all" to "very much so" (0-4), and from "almost never" to "almost always" (0-4), respectively. Both direct scores and converted percentiles of each participant were considered for the interpretation of results.

The intensity and frequency of displaying anxiety symptoms were determined by the State-Trait Anxiety Inventory (STAI) [54,55]. This questionnaire includes a total of 40 items, 20 for the State Anxiety subscale (STAI-State) and 20 for the Trait Anxiety subscale (STAI-Trait). STAI-State evaluates the current state of anxiety by obtaining answers ranging from "not at all" to "very much so" (0-3) to several items (i.e., worry, apprehension, nervousness, tension and autonomic nervous system activation/arousal) depending on how they feel "at this moment". STAI-Trait assesses stable aspects of "anxiety proneness" or the frequency of feeling anxious (i.e., general states of confidence, calmness, or security). STAI-Trait answers range from "almost never" to "almost always" (0-3). Both direct scores and converted percentiles of each participant were also considered for the interpretation of results.

\subsection{CPAP Usage}

A CPAP device (Oximesa oxygen company, Madrid, Spain), as well as a tube with an embedded heating circuit and a humidifier, were provided to each participant after the baseline assessment as medically recommended. In addition, an appropriate mask was selected according to participant's facial dimensions. A qualified sleep physician instructed participants on how to use the CPAP automatic mode during the first week in order to manually program the CPAP pressure during the rest of the intervention period (CPAP pressure was usually the 95th centile). CPAP use and pressure were defined as the average of (i) daily usage of CPAP (h/per night), and (ii) daily pressure of CPAP (mmHg), respectively, in accordance with clinical guidelines [56]. 


\subsection{Sample Size Calculation}

The sample size calculation was performed expecting an effect size of -0.5 on BDI-FS score after CPAP intervention with a variability (SD) of 1 (based on a previous study [52] and on our own previous observations), using the formula $n=\frac{2\left(Z_{\alpha}+Z_{1-\beta}\right)^{2} \sigma^{2}}{\Delta^{2}}$. A sample size of $\approx 36$ participants was therefore expected to provide a statistical power of $85 \%\left(Z_{(1-\beta)}=1.28\right)$ considering a type I error of 0.05 $\left(Z_{\alpha}=1.96\right)$ [57]. Assuming a maximum loss of $20 \%$ at follow-up, we decided to recruit a minimum of 45 participants.

\subsection{Statistical Analysis}

Descriptive parameters are expressed as the mean (SD) for continuous variables and number of patients (\%) for categorical variables. Visual check histograms, quantile-quantile (Q-Q) plots and the Shapiro-Wilk test were used to confirm the normality of our data. Unpaired $t$-student tests were performed to study potential differences between sexes at baseline assessment. As no interactions by sex were noted, the appropriateness of fitting models included both men and women.

Paired $t$-student tests were conducted to study changes in AHI, Epworth sleepiness score, BDI-FS score, STAI-State and STAI-Trait scores, and IDER-State and IDER-Trait scores after CPAP therapy. Standardized effect size coefficients $(d)$ were computed as the mean difference between mean baseline and mean post-intervention values, divided by mean baseline standard deviation $\boldsymbol{d}=c(d f) \cdot\left[\left(\overline{\boldsymbol{X}}_{p r e, E}-\overline{\boldsymbol{X}}_{p o s, E}\right) / \overline{\boldsymbol{S}}_{p r e, E}\right]$ where $c(d f)$ is a correction factor for small samples [58].

Similar analyses were separately performed (i) on overweight and obese patients, (ii) on patients with moderate and severe OSA, and (iii) on men and women. An analysis of covariance was additionally conducted to examine whether or not the above-mentioned changes persisted after controlling for sex, age, CPAP use and BMI.

Simple linear regression models were built to investigate (i) the association of the Epworth sleepiness score, BDI-FS score, STAI-State and STAI-Trait scores, and IDER-State and IDER-Trait scores with AHI, and (ii) the association of changes in the above-mentioned outcomes with changes in AHI. Multiple linear regression models were also performed to test these associations adjusting for sex (Model 1), age (Model 2), CPAP use (Model 3), and BMI (Model 4). Additionally, a simple linear regression was conducted in order to study the association of BDI-FS score, STAI-State and STAI-Trait scores, and IDER-State and IDER-Trait scores with Epworth sleepiness scores and BMI.

The Statistical Package for Social Sciences (SPSS, v. 22.0, IBM SPSS Statistics, IBM Corporation) was used to perform the analyses, and the GraphPad Prism 5 (GraphPad Software, San Diego, CA, USA) were used to build graphical plots. The level of significance was set at $<0.05$.

\section{Results}

Table 1 shows the baseline characteristics of the study participants. CPAP use ranged from 1.0 to $8.1 \mathrm{~h}$. Differences by sex where only statistically significant when considering age of participants. No significant changes in BMI were observed after the twelve-week CPAP intervention $(p>0.5)$. Overall, no presence of cognitive-affective symptoms of depression and anxiety were observed in the study participants (see Table 1 percentiles).

Figure 1 shows changes in AHI and sleepiness after CPAP treatment. Significant reductions in AHI $(p<0.001, d=1.809$; Figure $1 \mathrm{~A}$ and Table 2$)$ and Epworth sleepiness score $(p<0.001, d=0.612$; Figure 1B and Table 2) were observed. 
Table 1. Descriptive characteristic of participants.

\begin{tabular}{|c|c|c|c|c|c|c|c|c|c|}
\hline \multirow[b]{2}{*}{ Age (years) } & \multirow{2}{*}{$\begin{array}{l}N \\
48\end{array}$} & \multicolumn{2}{|c|}{ All } & \multirow{2}{*}{$\frac{N}{33}$} & \multicolumn{2}{|c|}{ Men } & \multirow{2}{*}{$\frac{N}{15}$} & \multicolumn{2}{|c|}{ Women } \\
\hline & & 54.5 & $(13.1)$ & & 51.0 & $(12.0)$ & & 62.0 & $(12.6)^{*}$ \\
\hline Body mass index $\left(\mathrm{kg} / \mathrm{m}^{2}\right)$ & 48 & 32.8 & (6.8) & 33 & 33.5 & (7.3) & 15 & 31.2 & (5.4) \\
\hline Smokers $(n, \%)$ & 48 & 8 & $(16.7)$ & 33 & 7 & $(21.2)$ & 15 & 1 & (6.7) \\
\hline Alcohol consumers $(n, \%)$ & 48 & 5 & $(10.4)$ & 33 & 5 & $(15.2)$ & 15 & 0 & $(0.0)$ \\
\hline \multicolumn{10}{|l|}{ OSA severity classification } \\
\hline Moderate OSA $(n, \%)$ & 48 & 13 & $(27.1)$ & 33 & 8 & $(24.2)$ & 15 & 5 & (33.3) \\
\hline Severe OSA $(n, \%)$ & 48 & 35 & $(72.9)$ & 33 & 25 & $(75.8)$ & 15 & 10 & $(66.7)$ \\
\hline Apnoea-hypopnoea index $(n)$ & 48 & 44.2 & $(22.5)$ & 33 & 47.0 & $(23.3)$ & 15 & 38.0 & $(19.9)$ \\
\hline CPAP use (h) & 48 & 5.7 & $(1.8)$ & 33 & 5.9 & $(1.6)$ & 15 & 5.3 & $(2.2)$ \\
\hline $\mathrm{CPAP}$ pressure $(\mathrm{mmHg})$ & 48 & 9.7 & (1.8) & 33 & 9.5 & $(2.0)$ & 15 & 9.9 & (1.2) \\
\hline \multicolumn{10}{|l|}{ Epworth questionnaire } \\
\hline Epworth sleepiness score & 47 & 9.85 & $(5.27)$ & 32 & 9.94 & $(5.16)$ & 15 & 9.67 & $(5.69)$ \\
\hline \multicolumn{10}{|l|}{ BDI-FS questionnaire } \\
\hline BDI-FS score & 48 & 2.92 & (3.05) & 33 & 2.82 & $(2.90)$ & 15 & 3.13 & $(3.44)$ \\
\hline Sadness & 48 & 0.25 & $(0.48)$ & 33 & 0.24 & $(0.44)$ & 15 & 0.27 & $(0.59)$ \\
\hline Pessimism & 48 & 0.50 & $(0.74)$ & 33 & 0.52 & $(0.76)$ & 15 & 0.47 & $(0.74)$ \\
\hline Past failure & 48 & 0.29 & $(0.65)$ & 33 & 0.27 & $(0.52)$ & 15 & 0.33 & $(0.9)$ \\
\hline Loss of pleasure & 48 & 0.54 & $(0.74)$ & 33 & 0.55 & $(0.75)$ & 15 & 0.53 & $(0.74)$ \\
\hline Self-dislike & 48 & 0.48 & $(0.83)$ & 33 & 0.45 & $(0.75)$ & 15 & 0.53 & $(0.99)$ \\
\hline Self-criticalness & 48 & 0.77 & $(0.72)$ & 33 & 0.70 & $(0.81)$ & 15 & 0.93 & $(0.46)$ \\
\hline Suicidal thoughts & 48 & 0.08 & $(0.28)$ & 33 & 0.09 & $(0.29)$ & 15 & 0.07 & $(0.26)$ \\
\hline \multicolumn{10}{|l|}{ STAI questionnaire } \\
\hline STAI-State score & 46 & 20.11 & $(12.57)$ & 31 & 18.03 & $(12.82)$ & 15 & 24.40 & $(11.24)$ \\
\hline STAI-State score percentile ${ }^{a}$ & 46 & 57.50 & $(33.90)$ & 31 & 53.26 & $(37.24)$ & 15 & 66.27 & $(24.49)$ \\
\hline STAI-Trait score & 45 & 21.60 & (11.06) & 30 & 20.97 & (11.81) & 15 & 22.87 & $(9.64)$ \\
\hline STAI-Trait score percentile ${ }^{a}$ & 45 & 51.62 & $(32.07)$ & 30 & 53.50 & $(34.37)$ & 15 & 47.87 & $(27.61)$ \\
\hline \multicolumn{10}{|l|}{ IDER questionnaire } \\
\hline IDER-State score & 48 & 19.56 & $(5.67)$ & 33 & 18.82 & $(5.86)$ & 15 & 21.20 & $(5.03)$ \\
\hline IDER-State score percentile ${ }^{a}$ & 48 & 61.37 & (26.17) & 33 & 58.52 & $(28.28)$ & 15 & 67.67 & $(20.25)$ \\
\hline IDER-State euthymia score & 48 & 12.71 & $(3.51)$ & 33 & 12.21 & $(3.60)$ & 15 & 13.80 & $(3.14)$ \\
\hline IDER-State dysthymia score & 48 & 6.85 & $(2.59)$ & 33 & 6.61 & $(2.67)$ & 15 & 7.40 & $(2.38)$ \\
\hline IDER-Trait score & 48 & 18.42 & $(5.62)$ & 33 & 18.06 & $(5.33)$ & 15 & 19.20 & $(6.35)$ \\
\hline IDER-Trait score percentile ${ }^{a}$ & 48 & 50.21 & (32.09) & 33 & 50.88 & $(32.25)$ & 15 & 48.73 & $(32.82)$ \\
\hline IDER-Trait euthymia score & 48 & 11.46 & $(3.99)$ & 33 & 11.27 & $(3.83)$ & 15 & 11.87 & $(4.44)$ \\
\hline IDER-Trait dysthymia score & 48 & 6.96 & $(2.13)$ & 33 & 6.79 & $(1.98)$ & 15 & 7.33 & $(2.47)$ \\
\hline
\end{tabular}

Data are shown as the mean (standard deviation). * Significant differences between sexes were obtained from unpaired $t$-student tests $(p<0.05)$. ${ }^{\text {a }}$ Score percentile variables refer to the mean and standard deviation of the percentiles for STAI-State, STAI-Trait, IDER-State, and IDER-Trait. Abbreviations: OSA, obstructive sleep apnoea; CPAP, continuous positive airway pressure; BDI-FS, Beck Depression Inventory-Fast Screen; STAI, State and Trait Anxiety Inventory; IDER, State-Trait Depression Inventory.
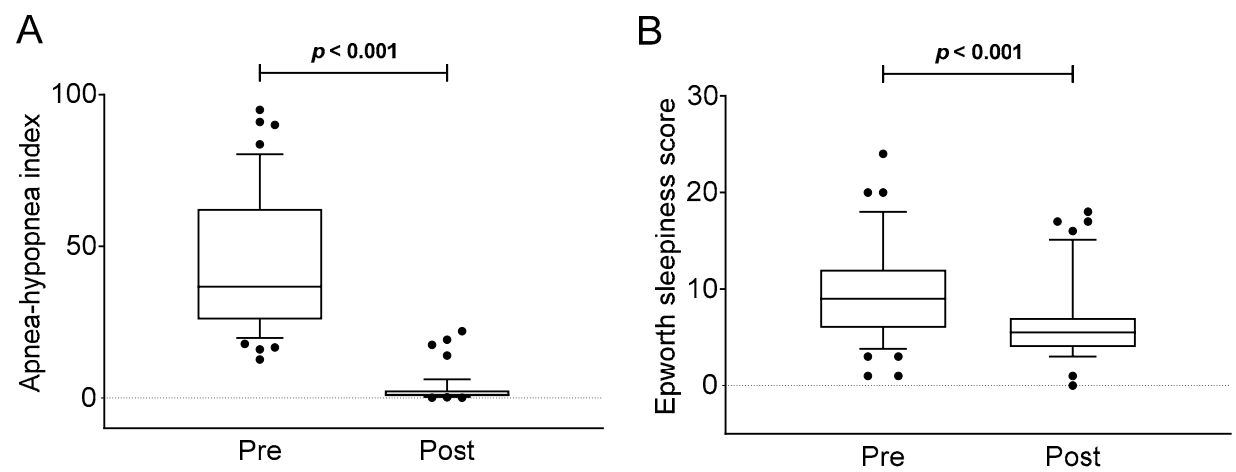

Figure 1. Apnoea-hypopnoea index (Panel A) and Epworth sleepiness score (Panel B) before and after the continuous positive airway pressure therapy. P value of Student's paired $t$-test. The data are shown as the median \pm interquartile range. 
Table 2. Apnoea-hypopnoea index, Epworth sleepiness score, BDI-FS score, STAI-State and STAI-Trait scores, and IDER-State and IDER-Trait scores before and after the CPAP intervention.

\begin{tabular}{|c|c|c|c|c|c|c|c|c|c|}
\hline & \multicolumn{3}{|c|}{$\begin{array}{c}\text { All } \\
(n=48)\end{array}$} & \multicolumn{3}{|c|}{$\begin{array}{c}\text { Men } \\
(n=33)\end{array}$} & \multicolumn{3}{|c|}{$\begin{array}{l}\text { Women } \\
(n=15)\end{array}$} \\
\hline & $\begin{array}{c}\text { Pre } \\
\text { Mean (SD) }\end{array}$ & $\begin{array}{c}\text { Post } \\
\text { Mean (SD) }\end{array}$ & $\begin{array}{c}\mathrm{d} \\
(95 \% \mathrm{CI})\end{array}$ & $\begin{array}{c}\text { Pre } \\
\text { Mean (SD) }\end{array}$ & $\begin{array}{c}\text { Post } \\
\text { Mean (SD) }\end{array}$ & $\begin{array}{c}\mathrm{d} \\
(95 \% \mathrm{CI})\end{array}$ & $\begin{array}{c}\text { Pre } \\
\text { Mean (SD) }\end{array}$ & $\begin{array}{c}\text { Post } \\
\text { Mean (SD) }\end{array}$ & $\begin{array}{c}\mathrm{d} \\
(95 \% \mathrm{CI})\end{array}$ \\
\hline $\begin{array}{l}\text { Epworth sleepiness } \\
\text { score }\end{array}$ & $9.85(5.27)$ & $6.57(4.14)$ & $\begin{array}{c}0.612 \\
(0.190 \text { to } 1.027)\end{array}$ & $9.94(5.16)$ & $6.28(4.46)$ & $\begin{array}{c}0.699 \\
(0.272 \text { to } 1.120)\end{array}$ & $9.67(5.69)$ & $7.20(3.41)$ & $\begin{array}{c}0.427 \\
(0.016 \text { to } 0.834)\end{array}$ \\
\hline BDI-FS score & $2.92(3.05)$ & $2.79(2.82)$ & $\begin{array}{c}0.042 \\
(-0.358 \text { to } 0.442)\end{array}$ & $2.82(2.90)$ & $2.67(3.12)$ & $\begin{array}{c}0.051 \\
(-0.349 \text { to } 0.451)\end{array}$ & $3.13(3.44)$ & 3.07 (2.09) & $\begin{array}{c}0.017 \\
(-0.383 \text { to } 0.417)\end{array}$ \\
\hline STAI-State score & $20.11(12.57)$ & $17.80(10.74)$ & $\begin{array}{c}0.181 \\
(-0.222 \text { to } 0.582)\end{array}$ & $18.03(12.82)$ & $15.29(9.98)$ & $\begin{array}{c}0.21 \\
(-0.193 \text { to } 0.611)\end{array}$ & $24.40(11.24)$ & $23.00(10.71)$ & $\begin{array}{c}0.123 \\
(-0.278 \text { to } 0.523)\end{array}$ \\
\hline STAI-Trait score & $21.60(11.06)$ & $16.96(10.26)$ & $\begin{array}{c}0.413 \\
(0.002 \text { to } 0.820)\end{array}$ & $20.97(11.81)$ & $14.23(9.07)$ & $\begin{array}{c}0.562 \\
(0.143 \text { to } 0.975)\end{array}$ & $22.87(9.64)$ & $22.40(10.62)$ & $\begin{array}{c}0.048 \\
(-0.352 \text { to } 0.448)\end{array}$ \\
\hline IDER-State score & $19.56(5.67)$ & $17.98(4.86)$ & $\begin{array}{c}0.274 \\
(-0.131 \text { to } 0.676)\end{array}$ & $18.82(5.86)$ & $17.15(4.79)$ & $\begin{array}{c}0.281 \\
(-0.125 \text { to } 0.684)\end{array}$ & $21.20(5.03)$ & $19.80(4.66)$ & $\begin{array}{c}0.274 \\
(-0.131 \text { to } 0.676)\end{array}$ \\
\hline $\begin{array}{c}\text { IDER-State } \\
\text { euthymia score }\end{array}$ & $12.71(3.51)$ & $11.54(3.34)$ & $\begin{array}{c}0.328 \\
(-0.079 \text { to } 0.732)\end{array}$ & $12.21(3.60)$ & $10.88(3.32)$ & $\begin{array}{c}0.364 \\
(-0.045 \text { to } 0.769)\end{array}$ & $13.80(3.14)$ & $13.00(2.98)$ & $\begin{array}{c}0.250 \\
(-0.155 \text { to } 0.652)\end{array}$ \\
\hline $\begin{array}{c}\text { IDER-State } \\
\text { dysthymia score }\end{array}$ & $6.85(2.59)$ & $6.44(1.91)$ & $\begin{array}{c}0.156 \\
(-0.246 \text { to } 0.556)\end{array}$ & $6.61(2.67)$ & 6.27 (1.79) & $\begin{array}{c}0.125 \\
(-0.276 \text { to } 0.525)\end{array}$ & $7.40(2.38)$ & $6.80(2.18)$ & $\begin{array}{c}0.248 \\
(-0.156 \text { to } 0.650)\end{array}$ \\
\hline IDER-Trait score & $18.42(5.62)$ & $16.73(4.23)$ & $\begin{array}{c}0.296 \\
(-0.110 \text { to } 0.699)\end{array}$ & $18.06(5.33)$ & $16.55(4.79)$ & $\begin{array}{c}0.279 \\
(-0.126 \text { to } 0.682)\end{array}$ & $19.20(6.35)$ & $17.13(2.72)$ & $\begin{array}{c}0.321 \\
(-0.086 \text { to } 0.725)\end{array}$ \\
\hline $\begin{array}{c}\text { IDER-Trait } \\
\text { euthymia score }\end{array}$ & $11.46(3.99)$ & $9.83(3.09)$ & $\begin{array}{c}0.402 \\
(-0.008 \text { to } 0.808)\end{array}$ & $11.27(3.83)$ & $9.76(3.44)$ & $\begin{array}{c}0.388 \\
(-0.022 \text { to } 0.794)\end{array}$ & $11.87(4.44)$ & $10.00(2.24)$ & $\begin{array}{c}0.415 \\
(0.004 \text { to } 0.822)\end{array}$ \\
\hline $\begin{array}{c}\text { IDER-Trait } \\
\text { dysthymia score }\end{array}$ & $6.96(2.13)$ & $6.90(1.81)$ & $\begin{array}{c}0.028 \\
(-0.372 \text { to } 0.428)\end{array}$ & $6.79(1.98)$ & 6.79 (1.97) & $\begin{array}{c}0.001 \\
(-0.399 \text { to } 0.401)\end{array}$ & $7.33(2.47)$ & $7.13(1.46)$ & $\begin{array}{c}0.080 \\
(-0.321 \text { to } 0.480)\end{array}$ \\
\hline
\end{tabular}

Data are shown as the mean (standard deviation). Abbreviations: BDI-FS, Beck Depression Inventory-Fast Screen; STAI, State and Trait Anxiety Inventory; IDER, State-Trait Depression Inventory; $\mathrm{CPAP}$, continuous positive airway pressure. 
Changes in general and state-trait depression symptoms, as well as in the intensity and frequency of displaying anxiety symptoms, can be seen in Figure 2. Significant reductions in STAI-Trait score $(p=0.005, d=0.413$; Figure 2C and Table 2), IDER-State $(p=0.020, d=0.274$; Figure 2D and Table 2) and IDER-Trait score ( $p=0.024, d=0.296$; Figure $2 \mathrm{G}$ and Table 2$)$ were observed, whereas no significant changes in BDI-FS ( $p=0.782, d=0.042$; Figure 2A and Table 2$)$ and STAI-State $(p=0.128, d=0.181$; Figure 2B and Table 2) scores were noted. Moreover, a significant decrease in IDER-State euthymia and IDER-Trait euthymia scores were found ( $p=0.017, d=0.328$ and $p=0.004, d=0.402$, respectively; Figure 2E,H, and Table 2), while no significant changes were observed in IDER-State dysthymia and IDER-Trait dysthymia scores after the CPAP intervention $(p=0.178, d=0.156$ and $p=0.852, d=0.028$, respectively; Figure 2F,I, and Table 2). All above-mentioned findings persisted not only after dividing our study sample in overweight and obese patients (Supplementary Figures S1 and S2), but also after categorizing our cohort as patients with moderate vs. severe OSA (Supplementary Figures S3 and S4) and after separating men and women (Supplementary Figures S5 and S6). These results did not change after controlling for sex, age, CPAP use and BMI.
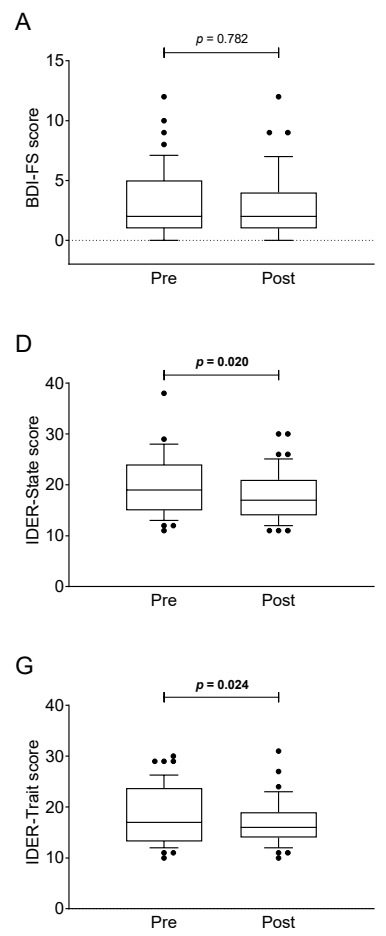
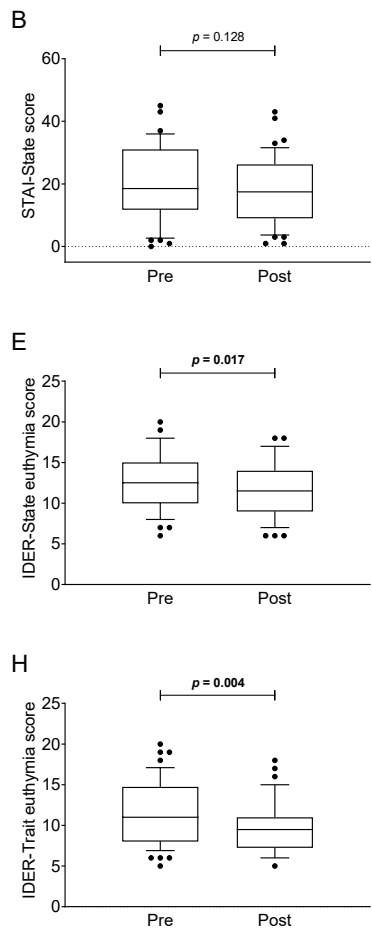
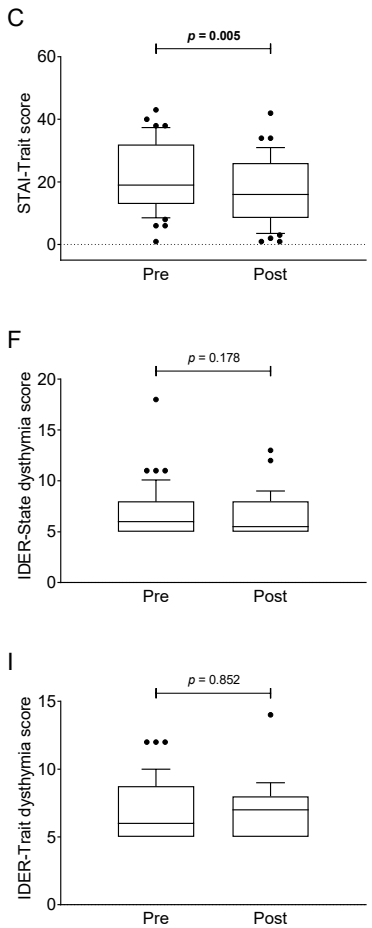

Figure 2. Beck Depression Inventory-FS (BDI-FS) score (Panel A), State and Trait Anxiety Inventory (STAI) scores (Panel B,C), and State-Trait Depression Inventory (IDER) scores (Panel D-I) before and after the continuous positive airway pressure therapy. $p$ value of Student's paired $t$-test. The data are shown as the median \pm interquartile range.

No association between Epworth sleepiness, BDI-FS, STAI-State, STAI-Trait, IDER-State, IDER-Trait, IDER-State euthymia, IDER-Trait euthymia, IDER-State dysthymia and IDER-Trait dysthymia scores, and AHI (Supplementary Figures S7 and S8; all $p>0.2$ ) was detected at baseline, which remained non-significant adjusting for several confounders (all $p>0.1$; Supplementary Table S1).

No significant associations were observed between changes in Epworth sleepiness, BDI-FS, STAI-State, STAI-Trait, IDER-State, or IDER-Trait, IDER-State euthymia, IDER-Trait euthymia, IDER-State dysthymia and IDER-Trait dysthymia scores and changes in AHI after CPAP therapy (all $p>0.15$; Supplementary Figures S9 and S10), which persisted after adding sex, age, CPAP use and BMI as covariates (all $p>0.16$; Supplementary Table S2).

No significant associations were found between BDI-FS, STAI-State, STAI-Trait, IDER-State, IDER-Trait, IDER-State euthymia, IDER-Trait euthymia, IDER-State dysthymia or IDER-Trait dysthymia 
scores and BMI (all $p>0.14$; Supplementary Figures S10 and S11). Similarly, Epworth sleepiness score was not related to BDI-FS, STAI-State, STAI-Trait, IDER-State nor IDER-Trait (all $p>0.6$; Supplementary Figures S11 and S12).

Additionally, a positive association was found between BMI and AHI ( $p=0.008)$, while no significant association was observed between BMI and Epworth sleepiness score $(p=0.694)$ (Supplementary Figure S13).

\section{Discussion}

The ADIPOSA study sought to elucidate the presence of non-overlapping symptoms of depression and anxiety in patients with moderate to severe OSA before and after a twelve-week CPAP treatment. As we expected, although certain cognitive-affective symptoms of depression and anxiety were found at baseline, scores of these symptoms were not of clinical relevance. Furthermore, the amelioration of depression and anxiety symptomatology after a twelve-week CPAP therapy was only statistically significant when considering changes in anxiety-trait and both euthymia (i.e., lack of positive affect) trait and state outcomes. Our findings therefore may elucidate what has been indicated in previous research regarding a potential overestimation of depression and anxiety disturbances in OSA due to overlapping somatic symptoms found in both OSA and depression/anxiety, which are included in the scales commonly used for the assessment of these symptoms [59].

OSA and depression are both prevalent adverse medical and psychological conditions independently related to obesity and unhealthy lifestyles, sharing common diagnostic criteria such as daytime sleepiness, insomnia, fatigue and poor quality of life [34]. Therefore, there are inconsistent findings regarding the direct relationship between these conditions [34,59]. Our results indicated that, when solely assessing non-overlapping depression symptoms-i.e., cognitive-affective symptoms - patients with OSA did not display a depression level of clinical relevance since scores in BDI-FS and percentiles in IDER were under 4 and 75 , respectively [49,51]. This finding is in accordance with previous epidemiological research emphasising that depression prevalence on OSA drastically varies from $68.33 \%$ to $7.59 \%$ depending on whether the depression questionnaire used included overlapping symptoms or not, respectively [59].

Furthermore, the great impact of the different assessment tools used for depression in OSA may also be the key factor explaining the controversy found in research on the effectiveness of CPAP treatment in reducing these mood disturbances [34]. According to our results, there were no general changes in depression symptoms measured with BDI-FS on patients with moderate to severe OSA after a twelve-week CPAP use. Nonetheless, we found statistically significant specific changes in both depression state and depression trait from baseline to posttreatment when measuring with IDER. Although these results may appear controversial at first glance, they expose an original and remarkable difference which has not previously been addressed in this field. While BDI-FS measures cognitive-affective depression symptoms based on negative affect exclusively, IDER assesses not only the high negative affect (i.e., dysthymia) found in depression but also the lack of positive affect (i.e., euthymia), a defining factor of this mood disorder [60]. Our results indicate changes in depression symptoms after CPAP use only when considering positive affect, i.e., patients with OSA tended to interpret situations more optimistically or feel more positive emotions such as joy, happiness and hope after CPAP use, although the intensity and frequency of feeling negative emotions remained unchanged. Consistent with previous research [60], low positive affect is the distinctive feature of depression whereas high negative affect is a component of both depression and anxiety, so an improvement in the tendency of feeling negative emotions would require reductions in both depression and anxiety symptoms.

This noteworthy result may be of relevance to clinical and research practice as, although negative affect has been associated to non-compliance to CPAP use [61], positive affect has generally been closely related to lower allostatic load profiles including neuroendocrine, inflammatory, cardiovascular and metabolic biomarkers such as levels of cortisol, C-reactive protein, systolic blood pressure, diastolic 
blood pressure, heart rate, total cholesterol, triglycerides, low-density lipids, high-density lipids, albumin, glucose, $\mathrm{HbA1c}$, and waist circumference [62-64]. As alterations of these neuroendocrine, inflammatory, cardiovascular and metabolic markers, in turn, are causes and consequences of not only OSA but also other severe chronic conditions $[65,66]$, addressing positive affect may play an important role in the assessment and treatment of these conditions.

Regarding potential differences on cognitive-affective depression symptoms by sex, BMI and OSA severity, there were no differences in the presence of these symptoms mediated by any of these variables. These results are in accordance with previous epidemiological studies where depression was not correlated with sex, BMI or OSA severity [11]. In contrast, other studies found higher prevalence rates of depression in women and in those with higher BMI and severe OSA [67]. As previously noted, these inconsistent findings may be explained by the cofounder variables between OSA and depression and, therefore, the scales frequently used in observational studies. Similarly, changes found in depression symptoms (i.e., euthymia) after CPAP therapy in our study were not related to sex, age, BMI, CPAP compliance, changes in AHI nor daytime sleepiness. A preceding study with similar results highlighted that changes in mood disturbances after CPAP use, rather than simply and directly related to reduced AHI or daytime sleepiness, are linked to an increased quality of life of these patients [68], which once again exposes the complex and still unclear relationship between OSA and depression.

The association between OSA and anxiety has also been consistently established throughout a large number of epidemiological research $[11,69]$. In our study, after a twelve-week CPAP treatment, patients with OSA showed significant reductions in the anxiety-trait outcome, which has also been found in previous research [35]. Thus, patients with moderate to severe OSA, although displaying transitory symptoms of nervousness, tension and/or apprehension, tended to perceive situations as less threatening or alarming than before CPAP use. These results may be mainly explained by the general increased quality of life of patients with OSA after CPAP treatment [27].

To our knowledge, this is the first study on the presence and changes after CPAP therapy of cognitive-affective depression and anxiety symptoms in patients with OSA including not only the measurement of dysthymia but also the distinctive component of depression, i.e., euthymia. Although the prevalence and treatment response of these symptoms in OSA have been widely addressed in previous epidemiological and original research [16-18,34-40], the use of mood disturbances scales including overlapping symptoms, as well as the non-consideration of euthymia as the distinctive feature of depression, have potentially led to inconsistencies and unclear results in this field. Our results therefore have robust clinical and research implications, further supporting the potential overestimation of depression and anxiety prevalence in patients with OSA found throughout the large body of literature in this field [59]. Due to mood disturbances such as depression being a specific symptom included in the diagnostic criteria of OSA [15], only cognitive-affective components of depression should be measured when establishing the diagnosis of this sleep-disordered breathing, using scales adjusted to medical patients in order to perform an accurate OSA diagnosis which in turn will determine the posterior treatment. Furthermore, this study adds an interesting and previously disregarded factor to the research on depression and OSA association, i.e., the distinction between dysthymia and euthymia when assessing and addressing mood disturbances in patients with this condition and others. As emphasised by the World Health Organisation, depression is an important leading cause of disease burden worldwide highly comorbid to the majority of chronic physical conditions [70]. Therefore, our main findings could be cautiously generalised to the assessment and treatment of depression in other chronic diseases such as type II diabetes mellitus, metabolic syndrome, asthma, angina and arthritis.

Nevertheless, our findings should be interpreted with caution as these are limited to the design and methodology followed in our study. The main limitation was the lack of a comparison (i.e., control) group which could have fully allowed us to determine the cause-effect relationship between treatment and results. The unequal number of men and women included in our sample, although consistent with the well-established higher prevalence of OSA in men [1], was another limitation. A balanced sample by sex could have been a determining factor in order to analyse potential differences between men and 
women previously found in this area. However, we did not find any interaction by sex in our study, which indicates that the effect of the intervention was similar in men and women. Another limitation of our study is that, as the sample included did not displayed depression nor anxiety symptoms of clinical relevance at baseline, potential benefits of CPAP therapy for the amelioration of these symptoms may not have been properly assessed. The measurement of daytime sleepiness, depression and anxiety symptoms by subjective measures, though widely used and reliable scales [47-55], may have also been a limitation as they are not as accurate as objective measures. Similarly, accurate measures of other interesting outcomes such as quality of life, exercise practice and nutritional habits, not included in our study, could have enabled us to analyse potential interactions of these variables on the occurrence and adjustment of depression and anxiety symptoms in OSA.

Future well-designed observational and experimental studies are therefore required to further support these evidences. In order to elucidate both the prevalence of mood disturbances and the effectiveness of OSA treatments for these symptoms, epidemiological studies and randomised controlled trials with larger and balanced samples should only include accurate measurements of non-overlapping cognitive-affective depression and anxiety symptoms adjusted to medical patients. Depression measurements, specifically, should not only include dysthymia or negative affect component but also lack of positive affect or euthymia, the idiosyncratic component of depression [60]. Finally, as quality of life and general well-being has been closely related to depression [71] —with sleep quality as a feasible mediating factor [72] -, further studies should also include appropriate measurements of these variables and others such as exercise practice and nutritional habits.

\section{Conclusions}

The ADIPOSA study further highlights the essential need to use precise and accurate depression and anxiety scales adjusted to medical patients not only for assessment purposes but also for the treatment of these symptoms in patients with OSA. According to our findings, the prevalence of mood disturbances and anxiety in patients with this condition may have been overestimated throughout the large body of evidence, as we did not find a clinically relevant occurrence of non-overlapping depression and anxiety symptoms. The distinction of both dysthymia and euthymia components of depression may also be crucial when assessing treatment effects on this mood disturbance. In this regard, we found that a twelve-week CPAP therapy was specifically effective at improving the lack of positive affect, a potential health-protective factor of relevance. However, not until depression and anxiety disorders related to chronic diseases are accurately measured in clinical and research settings will it be possible to obtain robust conclusions on occurrence and amelioration after medical and/or psychological treatment of these disturbances.

Supplementary Materials: The following are available online at http://www.mdpi.com/2077-0383/8/12/2099/s1, Figure S1: Apnoea-hypopnoea index, Epworth sleepiness score, Beck Depression Inventory-FS (BDI-FS) score, and State and Trait Anxiety Inventory (STAI) scores before and after the continuous positive airway pressure therapy comparing patients with obstructive sleep apnoea having a body mass index (BMI) $<30 \mathrm{~kg} / \mathrm{m}^{2} \mathrm{vs} . \geq 30 \mathrm{~kg} / \mathrm{m}^{2}$, Figure S2: State-Trait Depression Inventory (IDER) scores, including euthymia and dysthymia specific values before and after the continuous positive airway pressure therapy comparing patients with obstructive sleep apnoea having a body mass index (BMI) $<30 \mathrm{~kg} / \mathrm{m}^{2} \mathrm{vs} . \geq 30 \mathrm{~kg} / \mathrm{m}^{2}$, Figure S3: Apnoea-hypopnoea index, Epworth sleepiness score, Beck Depression Inventory-FS (BDI-FS) score, and State and Trait Anxiety Inventory (STAI) scores before and after the continuous positive airway pressure therapy comparing patients with moderate (AHI $<30)$ vs. severe $(\mathrm{AHI} \geq 30$ ) obstructive sleep apnoea (OSA), Figure S4: State-Trait Depression Inventory (IDER) scores, including euthymia and dysthymia specific values before and after the continuous positive airway pressure therapy comparing patients with moderate $(\mathrm{AHI}<30)$ vs. severe $(\mathrm{AHI} \geq 30)$ obstructive sleep apnoea (OSA), Figure S5: Apnoea-hypopnoea index, Epworth sleepiness score, Beck Depression Inventory-FS (BDI-FS) score, and State and Trait Anxiety Inventory (STAI) scores before and after the continuous positive airway pressure therapy men vs. women, Figure S6: State-Trait Depression Inventory (IDER) scores, including euthymia and dysthymia specific values before and after the continuous positive airway pressure therapy men vs. women, Figure S7: Association of the Epworth sleepiness score, the Beck Depression Inventory-FS (BDI-FS) score, and the State and Trait Anxiety Inventory (STAI) scores with the apnoea-hypopnoea index, Figure S8: Association of the State-Trait Depression Inventory (IDER) scores including euthymia and dysthymia specific values with the apnoea-hypopnoea index, Figure S9: Association of changes in the Epworth sleepiness score, the Beck 
Depression Inventory-FS (BDI-FS) score, and the State and Trait Anxiety Inventory (STAI) scores with changes in the apnoea-hypopnoea index after a post-continuous positive airway pressure therapy, Figure S10: Association of changes in the State-Trait Depression Inventory (IDER) scores including euthymia and dysthymia specific values with changes in the apnoea-hypopnoea index after a post-continuous positive airway pressure therapy, Figure S11: Association of the Beck Depression Inventory-FS (BDI-FS) score, and the State and Trait Anxiety Inventory (STAI) scores with the Epworth sleepiness score and the body mass index, Figure S12: Association of the State-Trait Depression Inventory (IDER) scores including euthymia and dysthymia specific values with the Epworth sleepiness score and the body mass index, Figure S13: Association of body mass index (BMI) with apnoea-hypopnoea index (AHI) and the Epworth sleepiness score, Table S1: Association of the Epworth sleepiness score, the Beck Depression Inventory-Fast Screen (BDI-FS) score, the State and Trait Anxiety Inventory (STAI) score, and the State-Trait Depression Inventory (IDER) score with the apnoea-hypopnoea index adjusted for sex (Model 1), adjusted for age (Model 2), adjusted for continuous positive airway pressure use (Model 3) and adjusted for body mass index (Model 4), Table S2: Association of changes in the Epworth sleepiness score, the Beck Depression Inventory-FS (BDI-FS) score, the State and Trait Anxiety Inventory (STAI) score, and the State-Trait Depression Inventory (IDER) score with changes in the apnoea-hypopnoea index after a post-continuous positive airway pressure therapy adjusted for sex (Model 1), adjusted for age (Model 2), adjusted for continuous positive airway pressure use (Model 3) and adjusted for body mass index (Model 4).

Author Contributions: Conceptualization, A.C.-B., G.B.-C., G.S.-R. and C.M.-C.; Methodology, A.C.-B. and F.J.A.-G.; Formal analysis, F.J.A.-G. and A.C.-B.; Investigation, A.C.-B., and all authors; Resources, G.B.-C., J.R.R., G.S.-R. and C.M.-C.; Data curation, F.J.A.-G.; Writing-original draft preparation, A.C.-B. and F.J.A.-G.; Writing-review and editing, A.C.-B. and F.J.A.-G., and all authors.; Visualization, A.C.-B. and F.J.A.-G.; Supervision, A.C.-B., G.B.-C. and J.R.R.; Project administration, A.C.-B., F.J.A.-G., G.B.-C. and J.R.R.; Funding acquisition, A.C.-B., G.B.-C., F.J.A.-G., and J.R.R.

Funding: This research was supported by the Spanish Ministry of Education and Vocational Training, grant/award number FPU16/01093 and FPU14/04172. The study was also partially supported by the University of Granada Plan Propio de Investigación 2019-Programa Contratos-Puentes; University of Granada Plan Propio de Investigación 2016-Excellence actions: Unit of Excellence on Exercise and Health (UCEES); and the Junta de Andalucía, Consejería de Conocimiento, Investigación y Universidades (European Regional Development Funds, ref. SOMM17/6107/UGR).

Acknowledgments: The authors would like to express their gratitude to TEA Ediciones S.A. for the provision of psychological tests.

Conflicts of Interest: The authors declare no conflict of interest.

\section{References}

1. Senaratna, C.V.; Perret, J.L.; Lodge, C.J.; Lowe, A.J.; Campbell, B.E.; Matheson, M.C.; Hamilton, G.S.; Dharmage, S.C. Prevalence of obstructive sleep apnea in the general population: A systematic review. Sleep Med. Rev. 2017, 34, 70-81. [CrossRef] [PubMed]

2. World Health Organization. Obesity and Overweight. Available online: https://www.who.int/news-room/ fact-sheets/detail/obesity-and-overweight (accessed on 15 October 2019).

3. Carneiro-Barrera, A.; Díaz-Román, A.; Guillén-Riquelme, A.; Buela-Casal, G. Weight loss and lifestyle interventions for obstructive sleep apnoea in adults: Systematic review and meta-analysis. Obes. Rev. 2019, 20, 750-762. [CrossRef] [PubMed]

4. Jordan, A.S.; McSharry, D.G.; Malhotra, A. Adult obstructive sleep apnoea. Lancet 2014, 383, $736-747$. [CrossRef]

5. Chopra, S.; Rathore, A.; Younas, H.; Pham, L.V.; Gu, C.; Beselman, A.; Kim, I.Y.; Wolfe, R.R.; Perin, J.; Polotsky, V.Y.; et al. Obstructive sleep apnea dynamically increases nocturnal plasma free fatty acids, glucose, and cortisol during sleep. J. Clin. Endocrinol. Metab. 2017, 102, 3172-3181. [CrossRef]

6. Hoyos, C.M.; Drager, L.F.; Patel, S.R. OSA and cardiometabolic risk: What's the bottom line? Respirology 2017, 22, 420-429. [CrossRef]

7. Aurora, R.N.; Punjabi, N.M. Obstructive sleep apnoea and type 2 diabetes mellitus: A bidirectional association. Lancet Respir. Med. 2013, 1, 329-338. [CrossRef]

8. Holingue, C.; Wennberg, A.; Berger, S.; Polotsky, V.Y.; Spira, A.P. Disturbed sleep and diabetes: A potential nexus of dementia risk. Metabolism 2018, 84, 85-93. [CrossRef]

9. Bradley, T.D.; Floras, J.S. Obstructive sleep apnoea and its cardiovascular consequences. Lancet 2009, 373, 82-93. [CrossRef]

10. Jackson, M.L.; McEvoy, R.D.; Banks, S.; Barnes, M. Neurobehavioral impairment and CPAP treatment response in mild-moderate obstructive sleep apnea. J. Clin. Sleep Med. 2018, 14, 47-56. [CrossRef] 
11. Rezaeitalab, F.; Moharrari, F.; Saberi, S.; Asadpour, H.; Rezaeetalab, F. The correlation of anxiety and depression with obstructive sleep apnea syndrome. J. Res. Med. Sci. 2014, 19, 205-210.

12. Fu, Y.; Xia, Y.; Yi, H.; Xu, H.; Guan, J.; Yin, S. Meta-analysis of all-cause and cardiovascular mortality in obstructive sleep apnea with or without continuous positive airway pressure treatment. Sleep Breath. 2017, 21, 181-189. [CrossRef] [PubMed]

13. Tregear, S.; Reston, J.; Schoelles, K.; Phillips, B. Obstructive sleep apnea and risk of motor vehicle crash: Systematic review and meta-analysis. J. Clin. Sleep Med. 2009, 5, 573-581. [PubMed]

14. Jurado-Gámez, B.; Guglielmi, O.; Gude, F.; Buela-Casal, G. Workplace accidents, absenteeism and productivity in patients with sleep apnea. Arch. Bronconeumol. 2015, 51, 213-218. [CrossRef] [PubMed]

15. American Academy of Sleep Medicine. International Classification of Sleep Disorders, 3rd ed.; American Academy of Sleep Medicine: Darien, IL, USA, 2014.

16. Sharafkhaneh, A.; Giray, N.; Richardson, P.; Young, T.; Hirshkowitz, M. Association of psychiatric disorders and sleep apnea in a large cohort. Sleep 2005, 28, 1405-1411. [CrossRef]

17. Ohayon, M.M. The effects of breathing-related sleep disorders on mood disturbances in the general population. J. Clin. Psychiatry 2003, 64, 1195-1200. [CrossRef]

18. Douglas, N.; Young, A.; Roebuck, T.; Ho, S.; Miller, B.R.; Kee, K.; Dabscheck, E.J.; Naughton, M.T. Prevalence of depression in patients referred with snoring and obstructive sleep apnoea. Intern. Med. J. 2013, 43, 630-634. [CrossRef]

19. Scott, K.M. Depression, anxiety and incident cardiometabolic diseases. Curr. Opin. Psychiatry 2014, 27, 289-293. [CrossRef]

20. Kjelsberg, F.N.; Ruud, E.A.; Stavem, K. Predictors of symptoms of anxiety and depression in obstructive sleep apnea. Sleep Med. 2005, 6, 341-346. [CrossRef]

21. Knechtle, B.; Economou, N.T.; Nikolaidis, P.T.; Velentza, L.; Kallianos, A.; Steiropoulos, P.; Koutsompolis, D.; Rosemann, T.; Trakada, G. Clinical characteristics of obstructive sleep apnea in psychiatric disease. J. Clin. Med. 2019, 8, 534. [CrossRef]

22. Epstein, L.J.; Kristo, D.; Strollo, P.J.; Friedman, N.; Malhotra, A.; Patil, S.P.; Ramar, K.; Rogers, R.; Schwab, R.J.; Weaver, E.M.; et al. Clinical guideline for the evaluation, management and long-term care of obstructive sleep apnea in adults. J. Clin. Sleep Med. 2009, 5, 263-276.

23. Shokoueinejad, M.; Fernandez, C.; Carroll, E.; Wang, F.; Levin, J.; Rusk, S.; Glattard, N.; Mulchrone, A.; Zhang, X.; Xie, A.; et al. Sleep apnea: A review of diagnostic sensors, algorithms, and therapies. Physiol. Meas. 2017, 38, R204-R252. [CrossRef] [PubMed]

24. Sánchez, A.I.; Martínez, P.; Miró, E.; Bardwell, W.A.; Buela-Casal, G. CPAP and behavioral therapies in patients with obstructive sleep apnea: Effects on daytime sleepiness, mood, and cognitive function. Sleep Med. Rev. 2009, 13, 223-233. [CrossRef] [PubMed]

25. Jurado-Gámez, B.; Guglielmi, O.; Gude-Sampedro, F.; Buela-Casal, G. Effect of CPAP therapy on job productivity and psychosocial occupational health in patients with moderate to severe sleep apnea. Sleep Breath. 2015, 19, 1293-1299. [CrossRef] [PubMed]

26. Jurado-Gámez, B.; Guglielmi, O.; Gude, F.; Buela-Casal, G. Effects of continuous positive airway pressure treatment on cognitive functions in patients with severe obstructive sleep apnoea. Neurologia 2016, 31, 311-318. [CrossRef] [PubMed]

27. Zhao, Y.Y.; Wang, R.; Gleason, K.J.; Lewis, E.F.; Quan, S.F.; Toth, C.M.; Morrical, M.; Rueschman, M.; Weng, J.; Ware, J.H.; et al. Effect of continuous positive airway pressure treatment on health-related quality of life and sleepiness in high cardiovascular risk individuals with sleep apnea: Best apnea interventions for research (Best AIR) trial. Sleep 2017, 40, zsx040. [CrossRef] [PubMed]

28. Loube, D.I.; Loube, A.A.; Erman, M.K. Continuous positive airway pressure treatment results in weight less in obese and overweight patients with obstructive sleep apnea. J. Am. Diet Assoc. 1997, 97, 896-897. [CrossRef]

29. Redenius, R.; Murphy, C.; O’Neill, E.; Al-Hamwi, M.; Zallek, S.N. Does CPAP lead to change in BMI? J. Clin. Sleep Med. 2008, 4, 205-209.

30. Drager, L.F.; Brunoni, A.R.; Jenner, R.; Lorenzi-Filho, G.; Bensenor, I.M.; Lotufo, P.A. Effects of CPAP on body weight in patients with obstructive sleep apnoea: A meta-analysis of randomised trials. Thorax 2015, 70, 258-264. [CrossRef] 
31. Shechter, A.; Airo, M.; Valentin, J.; Dugas, N.C.; Abdalla, M.; St-Onge, M.P.; Louh, I.K. Effects of continuous positive airway pressure on body composition in individuals with obstructive sleep apnea: A non-randomized, matched before-after study. J. Clin. Med. 2019, 8, 1195. [CrossRef]

32. Morgenthaler, T.I.; Kapen, S.; Lee-Chiong, T.; Alessi, C.; Boehlecke, B.; Brown, T.; Coleman, J.; Friedman, L.; Kapur, V.; Owens, J.; et al. Practice parameters for the medical therapy of obstructive sleep apnea. Sleep 2006, $29,1031-1035$.

33. Carneiro-Barrera, A.; Amaro-Gahete, F.J.; Díaz-Román, A.; Guillén-Riquelme, A.; Jurado-Fasoli, L.; Sáez-Roca, G.; Martín-Carrasco, C.; Ruiz, J.R.; Buela-Casal, G. Interdisciplinary weight loss and lifestyle intervention for obstructive sleep apnoea in adults: Rationale, design and methodology of the INTERAPNEA study. Nutrients 2019, 11, 2227. [CrossRef] [PubMed]

34. Harris, M.; Glozier, N.; Ratnavadivel, R.; Grunstein, R.R. Obstructive sleep apnea and depression. Sleep Med. Rev. 2009, 13, 437-444. [CrossRef] [PubMed]

35. Sánchez, A.I.; Buela-Casal, G.; Bermúdez, M.P.; Casas-Maldonado, F. The effects of continuous positive air pressure treatment on anxiety and depression levels in apnea patients. Psychiatry Clin. Neurosci. 2001, 55, 641-646. [CrossRef] [PubMed]

36. Bucks, R.S.; Nanthakumar, S.; Starkstein, S.S.; Hillman, D.R.; James, A.; McArdle, N.; Hatch, K.; Skinner, T.C. Discerning depressive symptoms in patients with obstructive sleep apnea: The effect of continuous positive airway pressure therapy on Hamilton Depression Rating Scale symptoms. Sleep 2018, 41, zsy178. [CrossRef] [PubMed]

37. Bhat, S.; Gupta, D.; Akel, O.; Polos, P.G.; DeBari, V.A.; Akhtar, S.; McIntyre, A.; Ming, S.X.; Upadhyay, H.; Chokroverty, $\mathrm{S}$. The relationships between improvements in daytime sleepiness, fatigue and depression and psychomotor vigilance task testing with CPAP use in patients with obstructive sleep apnea. Sleep Med. 2018, 49, 81-89. [CrossRef] [PubMed]

38. Campos-Rodriguez, F.; Asensio-Cruz, M.I.; Cordero-Guevara, J.; Jurado-Gamez, B.; Carmona-Bernal, C.; Gonzalez-Martinez, M.; Troncoso, M.F.; Sanchez-Lopez, V.; Arellano-Orden, E.; Garcia-Sanchez, M.I.; et al. Effect of continuous positive airway pressure on inflammatory, antioxidant, and depression biomarkers in women with obstructive sleep apnea: A randomized controlled trial. Sleep 2019, 42, zsz145. [CrossRef]

39. Haensel, A.; Norman, D.; Natarajan, L.; Bardwell, W.A.; Ancoli-Israel, S.; Dimsdale, J.E. Effect of a 2 week CPAP treatment on mood states in patients with obstructive sleep apnea: A double-blind trial. Sleep Breath. 2007, 11, 239-244. [CrossRef]

40. Gagnadoux, F.; Le Vaillant, M.; Goupil, F.; Pigeanne, T.; Chollet, S.; Masson, P.; Bizieux-Thaminy, A.; Humeau, M.P.; Meslier, N. Depressive symptoms before and after long-term CPAP therapy in patients with sleep apnea. Chest 2014, 145, 1025-1031. [CrossRef]

41. Hamilton, M. A rating scale for depression. J. Neurol. Neurosurg. Psychiatry 1960, 23, 56-62. [CrossRef]

42. Beck, A.T.; Ward, C.H.; Mendelson, M.; Mock, J.; Erbaugh, J. An inventory for measuring depression. Arch. Gen. Psychiatry 1961, 4, 561-571. [CrossRef]

43. Beck, A.T.; Epstein, N.; Brown, G.; Steer, R.A. An inventory for measuring clinical anxiety: Psychometric properties. J. Consult. Clin. Psychol. 1988, 56, 893-897. [CrossRef] [PubMed]

44. Kapur, V.K.; Auckley, D.H.; Chowdhuri, S.; Kuhlmann, D.C.; Mehra, R.; Ramar, K.; Harrod, C.G. Clinical Practice Guideline for Diagnostic Testing for Adult Obstructive Sleep Apnea: An American Academy of Sleep Medicine Clinical Practice Guideline. J. Clin. Sleep Med. 2017, 13, 479-504. [CrossRef] [PubMed]

45. Masa, J.F.; Corral, J.; Pereira, R.; Duran-Cantolla, J.; Cabello, M.; Hernández-Blasco, L.; Monasterio, C.; Alonso, A.; Chiner, E.; Rubio, M.; et al. Effectiveness of home respiratory polygraphy for the diagnosis of sleep apnoea and hypopnoea syndrome. Thorax 2011, 66, 567-573. [CrossRef] [PubMed]

46. Berry, R.B.; Budhiraja, R.; Gottlieb, D.J.; Gozal, D.; Iber, C.; Kapur, V.K.; Marcus, C.L.; Mehra, R.; Parthasarathy, S.; Quan, S.F.; et al. Rules for scoring respiratory events in sleep: Update of the 2007 AASM manual for the scoring of sleep and associated events. Deliberations of the sleep apnea definitions task force of the American Academy of Sleep Medicine. J. Clin. Sleep Med. 2012, 8, 597-619. [CrossRef] [PubMed]

47. Johns, M.W. A new method for measuring daytime sleepiness: The Epworth sleepiness scale. Sleep 1991, 14, 540-545. [CrossRef] 
48. Chiner, E.; Arriero, J.M.; Signes-Costa, J.; Marco, J.; Fuentes, I. Validation of the Spanish version of the Epworth Sleepiness Scale in patients with a sleep apnea syndrome. Arch. Bronconeumol. 1999, 35, 422-427. [CrossRef]

49. Beck, A.T.; Guth, D.; Steer, R.A.; Ball, R. Screening for major depression disorders in medical inpatients with the Beck Depression Inventory for Primary Care. Behav. Res. Ther. 1997, 35, 785-791. [CrossRef]

50. Sanz, J.; Izquierdo, A.; García-Vera, M.P. Departamento de I+D Pearson Clinical \& Talent Assessment. In BDI-FS, Inventario de Depresión de Beck Para Pacientes Médicos; Pearson: Madrid, Spain, 2011.

51. Spielberger, C.D.; Agudelo, D.; Buela-Casal, G. Inventario de Depresión Estado/Rasgo (IDER); TEA Ediciones: Madrid, Spain, 2008.

52. Law, M.; Naughton, M.T.; Dhar, A.; Barton, D.; Dabscheck, E. Validation of two depression screening instruments in a sleep disorders clinic. J. Clin. Sleep Med. 2014, 10, 683-688. [CrossRef]

53. Poole, H.; Bramwell, R.; Murphy, P. The utility of the Beck Depression Inventory Fast Screen (BDI-FS) in a pain clinic population. Eur. J. Pain 2009, 13, 865-869. [CrossRef]

54. Spielberger, C.D.; Gorsuch, R.; Lushene, R. Manual for the State-Trait Anxiety Inventory; Consulting Psychologist Press: Palo Alto, CA, USA, 1970.

55. Buela-Casal, G.; Guillén-Riquelme, A.; Seisdedos-Cubero, N. Cuestionario de Ansiedad Estado-Rasgo: Adaptación española, 9th ed.; TEA Ediciones: Madrid, Spain, 2016.

56. Polysomnography Task Force; American Sleep Disorders Association Standards of Practice Committee. Practice parameters for the indications for polysomnography and related procedures. Sleep 1997, 20, 406-422. [CrossRef]

57. Shaffer, M.L.; Chinchilli, V.M. Including multiple imputation in a sensitivity analysis for clinical trials with treatment failures. Contemp. Clin. Trials 2007, 28, 130-137. [CrossRef] [PubMed]

58. Morris, S.B. Distribution of the standardized mean change effect size for meta-analysis on repeated measures. Br. J. Math. Stat. Psychol. 2000, 53, 17-29. [CrossRef] [PubMed]

59. Nanthakumar, S.; Bucks, R.S.; Skinner, T.C. Are we overestimating the prevalence of depression in chronic illness using questionnaires? Meta-analytic evidence in obstructive sleep apnoea. Health Psychol. 2016, 35, 423-432. [CrossRef] [PubMed]

60. Watson, D.; Clark, L.A.; Carey, G. Positive and negative affectivity and their relation to anxiety and depressive disorders. J. Abnorm. Psychol. 1988, 97, 346-353. [CrossRef]

61. Copur, A.S.; Erik Everhart, D.; Zhang, C.; Chen, Z.; Shekhani, H.; Mathevosian, S.; Loveless, J.; Watson, E.; Kadri, I.; Wallace, L.; et al. Effect of personality traits on adherence with positive airway pressure therapy in obstructive sleep apnea patients. Sleep Breath. 2018, 22, 369-376. [CrossRef]

62. Schenk, H.M.; Jeronimus, B.F.; van der Krieke, L.; Bos, E.H.; de Jonge, P.; Rosmalen, J.G.M. Associations of positive affect and negative affect with allostatic load: A lifelines cohort study. Psychosom. Med. 2018, 80, 160-166. [CrossRef]

63. Steptoe, A.; O’Donnell, K.; Badrick, E.; Kumari, M.; Marmot, M. Neuroendocrine and inflammatory factors associated with positive affect in healthy men and women: The Whitehall II study. Am. J. Epidemiol. 2008, 167, 96-102. [CrossRef]

64. Steptoe, A.; Gibson, E.L.; Hamer, M.; Wardle, J. Neuroendocrine and cardiovascular correlates of positive affect measured by ecological momentary assessment and by questionnaire. Psychoneuroendocrinology 2007, 32, 56-64. [CrossRef]

65. Mehra, R.; Teodorescu, M. Sleep, circadian disruption, and microbial-immune interactions: A new frontier. Chest 2018, 154, 740-742. [CrossRef]

66. Juster, R.P.; McEwen, B.S.; Lupien, S.J. Allostatic load biomarkers of chronic stress and impact on health and cognition. Neurosci. Biobehav. Rev. 2010, 35, 2-16. [CrossRef]

67. Aloia, M.S.; Arnedt, J.T.; Smith, L.; Skrekas, J.; Stanchina, M.; Millman, R.P. Examining the construct of depression in obstructive sleep apnea syndrome. Sleep Med. 2005, 6, 115-121. [CrossRef]

68. Kawahara, S.; Akashiba, T.; Akahoshi, T.; Horie, T. Nasal CPAP improves the quality of life and lessens the depressive symptoms in patients with obstructive sleep apnea syndrome. Intern. Med. 2005, 44, 422-427. [CrossRef]

69. Garbarino, S.; Bardwell, W.A.; Guglielmi, O.; Chiorri, C.; Bonanni, E.; Magnavita, N. Association of anxiety and depression in obstructive sleep apnea patients: A systematic review and meta-analysis. Behav. Sleep Med. 2018, 19, 1-23. [CrossRef] 
70. Moussavi, S.; Chatterji, S.; Verdes, E.; Tandon, A.; Patel, V.; Ustun, B. Depression, chronic diseases, and decrements in health: Results from the World Health Surveys. Lancet 2007, 370, 851-858. [CrossRef]

71. Wersebe, H.; Lieb, R.; Meyer, A.H.; Miche, M.; Mikoteit, T.; Imboden, C.; Hoyer, J.; Bader, K.; Hatzinger, M.; Gloster, A.T. Well-being in major depression and social phobia with and without comorbidity. Int. J. Clin. Health Psychol. 2018, 18, 201-208. [CrossRef]

72. Becker, N.B.; de Jesus, S.N.; Viseu, J.N.; Stobäus, C.D.; Guerreiro, M.; Domingues, R.B. Depression and quality of life in older adults: Mediation effect of sleep quality. Int. J. Clin. Health Psychol. 2018, 18, 8-17. [CrossRef]

(C) 2019 by the authors. Licensee MDPI, Basel, Switzerland. This article is an open access article distributed under the terms and conditions of the Creative Commons Attribution (CC BY) license (http://creativecommons.org/licenses/by/4.0/). 